Under this plan of treatment, intestinal antisepsis is furthered as is evidenced by the slight degree of tympanitis; absence of sordes on the teeth and especially by the character of the stools, which are much less frequent and are practically destitute of the very disagreeable odor that characterized the passages of patients before the introduction of treatment directed toward intestinal antisepsis.

High temperature is combated by cold sponging alone. No depressing antipyretics of any kind are used.

While I claim that the course of an attack is materially modified in ordinary cases, I do not claim guaiacol as a specific, for under its use during the last five years, (creasote being used part of the time, in place of guaiacol) I have lost two cases. Both of these died during the latter part of the third week, apparently of acute disorganization of the central nerve centers. The peculiar cause of death in connection with these two fatal cases remains to be explained. In each case a younger brother succumbed to the same disease, under different treatment, and under the care of other practitioners within a short period of time. The question naturally arises, was there not some peculiar absence of resisting power in the members of the families in which these cases occurred? The course of the disease in these fatal cases was not specially severe, but as already stated at some time during the latter part of the third week the nerve centers suddenly became involved and death resulted from asthenia.

No difficulty whatever has been experienced in the administration of the remedy, which is a feature of no little value in remedies for children.

\section{ACUTE LACUNAR DIPHTHERIA OF THE TONSILS.}

Read in the Section on Diseases of Children, at the Forty-sixth Annual Meeting of the American Medical Association, at Baltimore, Md., May 7-10, 1895 .

BY HENRY KOPLIK, M.D.

NEW YORK.

The writer has been induced to appear before your distinguished body to enlarge upon a theme previously brought to the notice of the profession, because he was convinced that the possible gravity of the apparently simple angina or lacunar tonsillitis was not yet generally accepted.

In a recent discussion upon the antitoxin treatment of diphtheria in the New York Academy of Medicine, one of the prominent speakers referring to bacteriologic diagnoses of diphtheria and especially those diagnoses which reveal the diphtheria not accompanied by membrane or parts of membrane in the throat, said that where the bacteriologic diagnosis of diphtheria, in the absence of clinical evidences, quarantines the house or separates a family from relatives and friends it is a sin against man. A further state. ment goes on to characterize the treatment of these mild cases in a diphtheria ward as a crime, etc. Another speaker while admitting that he would not give such patients who had no clinical evidences of diphtheria in their throats (membrane or parts of membrane) a clean bill of health, said it was difficult to know what to do with such cases. The terms "clinical diphtheria," "clinical evidences of diphtheria," were freely used and insisted upon as a diagnostic element in all cases where effective isolation is contemplated, at least so one would surmise from a perusal of the printed discussion.

The above is mentioned to show that there is still a wide gap between those who work purely clinical and those who combine the clinical with the findings of scientific research. In other words, we have not advanced a step since the time of the immortal Trousseau, in the diagnosis and prophylaxis of the dread disease, diphtheria, or we have no right to advance. No membrane, no diphtheria! This, to a certain number, is as true to-day as it was in the days of the great pupil of Bretanneau. The writer wishes here to point out the great danger which such a quasi-sentinental definition of diphtheria must needs carry with it. In 1891 the writer of this article, convinced that the gravity of a certain class of apparently simple anginas was not appreciated, undertook to investigate both from a clinical and bacteriologic standpoint all varieties of anginas in which there could scarcely be said to exist at the outset, at least, any clinical evidences locally of diphtheria. There was in these cases no form of typical membrane. No such systematic attempt had been undertaken, up to this time, to the writer's knowledge. The profession were told from time to time, that during epidemics of diphtheria, or even in the absence of epidemic influence, what seemed to be a simple lacunar tonsillitis might eventuate as a diphtheria. Trousseau in his lectures upon diphtheria cites forms of lacunar amygdalitis followed by paralyses. These paralyses were similar to those which followed in cases of membranous diphtheria. Trousseau hesitated to call these anginas "diphtheria," even though followed by paralyses. There was no membrane, and he preferred to think rather that paralysis could follow in rare instances a simple tonsillitis. His inability to supply the connecting link between the membranous and the non-membranous cases of diphtheria was the only thing which deterred this clinician from grouping the two classes of cases under one heading. We are certain that had the link been at hand at that time, his views would have been more distinctly radical than they were. He simply said that certain simple anginas might rarely be followed by paralyses.

In 1886 we find this question still a mooted one. Jacobi, of New York, and Fraenkel, of Berlin, both clinical leaders in their respective cities, differed widely in their views upon these cases, Fraenkel insisting that the ground taken by his clinical opponent, that diphtheria may run its course as a lacunar amygdalitis, was too sweeping. At this time also, no proof additional to that submitted by former writers was brought forward to prove the theses of which we are speaking. Every one argued from clinical deduction purely, and clinical deductions seemed to differ when grouped by different observers. After all had been said and done, every one hung to the doctrine of Friedreich, that lacunar amygdalitis was an infectious disease, but would go no further.

Henoch (edition 1893) in his classical hand-book upon diseases of children says in the article upon diphtheria: "I do not recognize the existence of a pharyngeal diphtheria in the form of a simple angina."

Escherich (1890, Henoch's Festschrift) while denying the existence of Löffler bacilli in the lacunar tonsillitis of young children, admits their existence in cases of catarrhal anginas of older children, in cases in which at no time has there been membrane or 
clinical evidences of diphtheria. Escherich, in this article, is guarded in his conclusions and reserves a decided classification for the opportunity given by a larger material than he had at his disposal.

Gerhardt was at this time also very decided in his view that danger lurked in the atypical diphtheria. He pointed out their capability of causing diphtheria in others.

In my first article (1891, New York Medical Journal) upon atypical cases of diphtheria, the first series of cases which were studied bacteriolngically were similar to those seen and described clinically by Trousseau, Gerhardt and Escherich, in which we find at the outset no typical membrane. Indeed, during the whole course of the disease, no membrane appeared to the naked eye. The cases were those of a child 4 years of age, having the symptoms and local manifestations of a simple catarrhal angina, but in whose throat large numbers of virulent Löfler bacilli were found. This case was associated in the same family with another severe non-membranous angina, in a sister aged 5 years, to whom I presumed the first had communicated the illness, and in this second case we had the same bacteriologic result as in the first case. During the whole illness, neither of these cases manifested any membrane. Fully a week after the first case had been taken ill, a baby $2 \frac{1}{2}$ years old in the same family became afflicted with fatal diphtheria, in which membrane and portions of mem. brane appeared in the throat, and which also involved the larynx. It will be thus seen that here was an almost faultless group of cases observed daily, in which two had the typical "diphtheria sine mem. brana," followed by a third case in the same family of true clinical diphthetia. It will naturally be asked, Was diphtheria suspected in the catarrhal cases? Working upon diphtheria at the time, scrapings were obtained from these throats, as shown in my paper, and fortumately several times, and tested upon animals; the results justified our early suspicions. The symptoms in these cases in which absolutely no membrane or points of membranous de. posit appears in the throat, I must say are equivocal. I have examined the throats of children who gave a set of clinical symptoms almost identical to the first class of cases and, as my work shows, I failed with equal precautions to find diphtheria bacilli. Thus the croupy coughs, the red throats, fever, enlarged glands and, I may say, even prostration upon which the stress was formerly laid, are not characteristic. The only way, it seems to the writer, to positively differentiate these cases is the bacteriologic method.

Another class of cases in which we must always be put upon our guard, are those in which a minute speck of membrane appears on the tonsil or uvula, looking like a drop of fibrinous secretion combined with a typical lacunar tonsillitis. These cases may be truly diphtheritic. Again, a third set of cases, showing pultaceous deposits of a stringy fibrinous character may prove to be nou-diphtheritic or vice versa. A fourth set of cases are those in which the tonsil is the seat of a necrotic ulcerative process, with no distinct membranous formation. In only one part of the tonsil do we find an excavation; the base of which is covered with specks of exudate. Henoch has described such cases, and many still speak of these cases as ulcerative sore throat. I have proved many of these cases to be distinctly true diphtheria. In some, the children are scarcely ill enough in the eyes of the parents to require treatment. It will be seen that there are forms of angina which are diphtheritic in their etiology, in which at no time are there manifestations of membrane, or such exudate as does appear is atypical.

Feer has confirmed the writer's work in the first set of cases, and it must now be admitted as firmly established that diphtheria "sine membrana" exists, though it introduces an unfortunate complexity into the problem of clinical diphtheria.

The most important class of atypical cases of diphtheria and perhaps the most common are those in which the appearances in the throat resemble in every detail the simple lacunar tonsillitis.

In 1894 I published a second paper, in which a series of consecutive cases, all giving the typical clinical picture of lacunar tonsillitis, were examined with special reference as to their diphtheritic or nondiphtheritic character. This paper adhered closely to this set of cases because in the first paper the material had spread over such a diverse field that it was not possible to judge the actual frequency of any particular set of the cases cited. In this series of lacunar tonsillitis, fully one-third of thirty-nine cases were shown to be true diphtheria. It was possible here, also, to divide the cases into groups as far as the severity and clinical symptoms were concerned.

The first group of cases are exceedingly mild; the patients show but little constitutional disturbance and complained but slightly of throat symptoms. Examination shows general hyperemia of the fauces, enlarged tonsils with open lacunæ. Some of the lacunæ showed an accumulation of yellow secretion at the surface opening. The lymph nodes at the angle of the jaw may or may not be enlarged.

The second group of lacunar diphtherias are those in which the local and constitutional symptoms are more pronounced. The patients show more prostration, the fever is quite high and there are other symptoms as pains in the limbs, furred tongue, etc. The tonsils are much enlarged and there exudes from the lacunæ a soft fibrinous exudate. There is no form of membrane anywhere on the tonsil and the lymph nodes are much enlarged. The plugs of these as also those of the first group contain Löffer bacilli.

The third group of cases are those which show distinctly malignant features from the outset. They do not remain purely lacunar after the first few days, and in this respect would resemble much, cases described by Heubner of membranous diphtheria, which early in their course resemble lacunar tonsillitis; and subsequently show coagulated exudate on the surface of the tonsil. The cases described by the writer belonging to this group, are truly septic in character, and beginning with a picture of lacunar tonsillitis, the infants the first day, even before the membrane is seen, have pallor and prostration which is quite characteristic and may at once put us on our guard. These are the cases which subsequently draw the nasal fossæ into the clinical picture. They are also the fatal cases. They begin as a lacunar tonsillitis and within forty-eight hours membrane and shreds of membrane are voided from behind the immensely swollen tonsils which completely occlude the fauces. It is not the intention of the writer to rehearse here the details of the bacteriologic examination of these cases of lacunar diphtheria of the tonsils, but there are some points which must be of vast and far-reaching importance, and which have been estab- 
lished by the writer and since confirmed by Flexner, Booker (Johns Hopkins Bulletin, March, 1895), and others. The Löffler bacilli of diphtheria, in the cases of lacunar diphtheria are found, not so much on the surface of the tonsil, but in the depths of the lacunæ, in the fibrinous pluge, which occlude the lumina of the lacunx. The bacilli are of equal virulence, whether obtained from the first group of mild cases or the third group of fatal septic lacunar diphtherias. The bacilli retain their virulence for weeks in the depths of the lacunæ, the patient being in apparent full convalescence, or the tonsils having returned to almost the normal size and appearance. In one case virulent bacilli were obtained from a lacunar plug of the tonsil in the third week of convalescence. A lacunar plug in one case, in which virulent bacilli had been isolated early in the disease showed non-virulent bacilli fully three weeks after the outset of the disease. In other words, virulent bacilli were replaced by the non-virulent variety in this particular lacunar amygdallitis.

Enough has been cited above, of the bacteriology of these cases, to show the importance of this class of cases of diphtheria. Too much weight can not be attached to these facts. We must not be turned aside by any fallacious arguments which continue to harp upon the desirability of a membrane in order to entitle a case to the dignity of the term, clinical diphtheria. This term, I believe, was first introduced into medicine by Trousseau. It is a landmark in the history of modern medicine, but it is time to protest against its use as a weapon with which to cast contempt on the class of cases concerned in this paper.

If prophylaxis is the ideal of modern hygiene, then the class of cases treated of in this paper, take a rank first in importance. Invocent in appearance, they are the means of disseminating a dread affection. Serious and unremitting isolation is the only method by which we can show our appreciation of their serious nature. Their importance crops out in the operating room constantly. At the last meeting of the American Pediatric Society, the writer of this paper insisted that those cases of tonsillotomy upon enlarged tonsils which were followed by membranous diphtheria, or even croup, were undoubtedly of the nature of the cases described in this paper. It has been shown by the writer that in these large tonsils, virulent diphtheria bacilli exist long into convalescence. As long as they are left to the natural fluids in the lacunæ no harm results to the patient, and we have even reason to believe, as pointed out in my second paper, that they gradually lose their original virulence. Cut this tonsil, however, and you expose to the propagation of the bacilli in the lacunæ the most favored of growing media, a freshly cut surface bathed in lymph, and a membrane results, in some cases spreading to the fauces and larynx. One case of this kind is enough to convince the most skeptical, and yet there are many such, doubtless, who are waiting for the case to occur to them.

Diagnosis.-How can we approach the diagnosis of these cases? The old methods, such as proposed by Henoch, only apply to cases which finally develop membrane or portions of membrane. If we wish, however, to pick out the pure lacunar diphtherias in which membrane never forms, we will find that our safest method is the bacteriologic test. To test the urine to wait for specks of membrane to appear, only delays matters and does not aid us, for we have not only albuminuria in the streptococcus tonsillitis, but also glandular swellings and prostration with low and high curves of temperature. The opponents of bacteriologic diagnosis say that the Löffler bacillus has been found on the normal mucous membrane. Would you call such a case diphtheria and isolate it? The answer to this fallacious argument is plain. The well authenticated cases in which investigators of acknowledged rank (Löffler, Roux) have found virulent bacilli on the normal mucous membrane, are exceedingly rare and exceptional. They are found in throats perhaps exposed to a diphtheria atmosphere. Since the inauguration of the simple crude methods of diagnosing a case of diphtheria by growing a culture and staining a few covers has come more and more into vogue, the bacilli in the normal throats. have multiplied in frequency. We would ask that methods showing such evident flaws be not taken too seriously. They are necessary in rapid hygienic work, but must not be brought forward as an argument.

Given an angina in which Löffler bacilli have been demonstrated to exist in large numbers, such a throat is diphtheritic and must be grouped with diphtheria, membranous or otherwise. It should be unmercifully isolated, whether it isolates the patient from friends and family or sends the patient into a contagious ward where severe cases of diphtheria are treated. It has been maintained that the placing of such cases among severer cases is an injustice to the patient. Those who have studied diphtheria since the discovery of Löffler must subscribe to the views brought forward by Escherich. These mild cases of diphtheria must be explained on the ground of immunity. They do not develop membrane and can not develop severe diphtheria, because in these particular individuals there is a natural or acquired immunity which protects them against the severer manifestations of the disease. If you place them, therefore, in a ward in which there are very severe cases of diphtheria, no more injustice is done to the mild case of diphtheria than would be done to a correspondingly mild case of measles placed in a ward with very severe and complicated measles.

On the other hand, these mild cases of diphtheria or lacunar diphtheria or diphtheria "sine membrana," are capable of communicating fatal or severe diphtheria to others. If we grant the above, which is the result of years of work at the bedside and in the laboratory, the principal arguments of the alarmists. fall to the ground.

CLINICAL EXPERIENCE WITH ANTITOXIN IN PRIVATE AND HOSPITAL PRACTICE IN THE TREATMENT OF DIPHTHERIA-(ALL, FORMS).

Read in the Section on Diseases of Children at the Forty-sixth Annual Meeting of the American Medical Association, at Baltimore, Md., May 7-10, 1895. BY LOUIS FISCHER, M.D.

Instructor in Disenses of Children at the New York Post-graduate Medical School and Hospital; Physician in Charge of the Messiah Home; Physician to the Children's Department of the German Polyklinik. NEW YORK.

My first successful case with antitoxin was pub. lished in the New York Medical Record, Oct. 6, 1894, in which a child 11 years old was attended by Dr. Gerlach. In this case I injected $5 \mathrm{ccm}$. of Aronson's antitoxin between the shoulder blades. The child was discharged, cured, on the fourth day. This pa- 